Medicine Updates

Faculty of medicine

April 2021,volume 5, issue 5 https://muj.journals.ekb.eg

dean@med.psu.edu.eg

vice_dean_postgraduate@med.psu.edu.eg

DOI: 10.21608/muj.2021.58727.1039

\title{
" Effect of Using Quality Tools on Assessment of Health Technical Institution Student's Knowledge and Practiceregarding COVID 19 "
}

Dr. Marwa Awad Mohamed: Nursing Science Teacher at Health

Technical Institute of Port Said- PhD.Sc. Faculty of Nursing- AinShams University.

Mona Mohamed Galal: Clinical Instructor at Technical Health Institute of Port Said- Faculty of Nursing- Suez Canal University Mona Ezz Eldin Seaoud: Head of Quality and Serology departments in

Port-Said blood transfusion center, M.Sc. Medicine, Suez Canal University

Liala Ahmed Rashwan: Infection Control Nursing specialist at Elmasah Elbahary hospitals- Faculty of Nursing- Suez Canal University

Menna Talla Ali Elghareeb: R.N. at Alsoliman Hospital, Faculty of Nursing Port Said University

Menna Talla Mohamed Khalil: R.N. at Alsoliman Hospital, Faculty of Nursing- Port Said University

Dalia Mahmoud Sultan: Pharmacist - Supervisor at Supply Chain Department at Assurance Authority

Zinab Abd Elghany Ramadan: Pharmacist -Drug store Supervisor at El- tadamon Hospital 


\section{ABSTRACT}

Quality Tools should positively effect on assessment of student's knowledge and practice regarding COVID 19. Aim of study was to study the effect of using quality tools on assessment of Health Technical Institution student's knowledge and practice regarding COVID 19. A descriptive study was utilized. Study was conducted at Port-Said City, in Health Technical Institute. The subjects involved all students at first and second academic year 2020 - 2021 and students' age ranged from 18 to 20 years old so, the sample size was 120 students. Data were collected through two quality tools; a questionnaire sheet, observational check lists. Results of study revealed that, majority (90\%) of students had correct knowledge about symptoms, mode of transmission and preemptive action of COVID-19, and (33\%) only knew about treatment approaches, but (49.20\%) knew about vaccine against COVID19. Almost half (53.30\%) of them preferred social media as primary sources of information followed. Most students showed a willingness to follow social distancing. Study concluded that using quality tools had positive effect on assessment of student's knowledge and practice regarding COVID 19 among health technical institute students. Authors recommended integrating a preemptive actions guideline regarding COVID 19 in the educational strategies at all educational stages.

Key words: Quality tools, Health Technical Institution Student, COVID 19.

\section{Introduction}

Seven old quality control tools are a set of the quality control tools that can be used for improving the performance of the production processes was invented by Dr. Kaoru Ishikawa was first guru of total quality management, who has been associated with the development and advocacy of using the seven quality control tools in the organizations for problem solving and process improvements (Kerzner, 2009).

Check sheets, Graphs (Trend Analysis), Histograms, Pareto charts, Causeand-effect diagrams, Scatter diagrams, Control charts are the basic quality control tools. So, these tools have the significant roles to monitor, obtain, analyze data for detecting and solving the problems of production processes, in order to facilitate the achievement of performance excellence in the organizations (Neyestani B., 2017).

In Wuhan, China, the first reported case of coronavirus disease 2019 (COVID-19) in December 2019, it has quickly spread globally, which prompting the World Health Organization to declare COVID-19 a pandemic on 12 March 2020 (WHO, 2020).

The novel coronavirus SARS-CoV2 and it is an acronym that stands for corona virus disease of 2019. COVID-19 is the name given by the World 
Health Organization on February 11, 2020 for the disease.

https://www.goodrx.com/blog/what-does-covid-19-mean-who-named-it/,2020)

COVID-19 primarily spreads person to person through close contact and contaminated surfaces, often via small droplets produced by the infected person through coughing, sneezing or talking. It is caused by a previously unreported strain of coronavirus, officially named Severe Acute Respiratory Syndrome Coronavirus 2 (SARS-CoV-2). The incubation period is around 5-14 days and common symptoms include shortness of breath fever and cough (Chen et al., 2020).

\section{Justification of the study}

Early detection and management of COVID-19 during adolescent stage among Technical Health Institution students can prevent many health problems during this stage because they represented big sector in the community. Moreover, it decreases mortality and morbidity rats. Health Technical Institution students represent a large segment of the community so, their knowledge and practice could have an important impact on the spread of a pandemic (Peng et al., 2020).

Nursing students in Health Technical Institution play an imperative role in health care services. During the COVID19 pandemic crisis, Nursing students are expected to spread attentiveness of key health and hygiene messages amongst communities and neighborhoods. Even staying at home, retaining social distance, wearing face masks, washing hands, etc. are quite a few measures that the governments' health departments are propagating. It is therefore of top importance that nursing students across the country have ample knowledge and awareness about all aspects of the disease including prevention strategies.

\section{$\underline{\text { Aim of Study }}$}

To study Using Quality Tools has Effect on Assessment of Health Technical Institution Student's Knowledge and Practice regarding COVID 19.

\section{This aim will be achieved through the following:}

○ Designing and implementing two quality tools about COVID19:

- Questionnaire form for measuring student's information.

- Standard performance list of precautionary measures.

○ Assessing student's knowledge and practices using quality tools.

\section{$\underline{\text { Research Ouestion }}$}

Does using quality tools improve assessment of Health Technical Institute student's knowledge and practice regarding COVID 19? 


\section{Methodology}

A descriptive study design was used to achieve the objectives. The study was conducted at Port-Said City, in Health Technical Institute. The subjects involved female student nurse at first and second academic year 2020 - 2021 and students' age characteristics from 18 to 20 years old so, the sample size was 120 students.

\section{Quality tools and technique of data collection:}

\section{A questionnaire sheet:}

It was adopted from Ministry of Health guidelines 2020. Divided into 4 parts

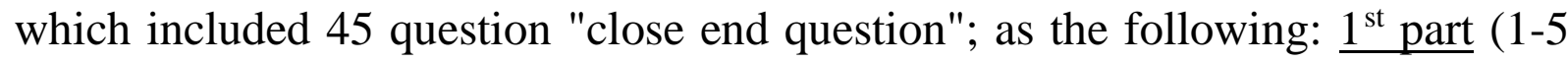
questions) to assess female general characteristics data or (socio-demographic data), $2^{\text {nd }}$ part (6-22 questions) to assess knowledge regarding COVID19 as disease, such as: concepts, causes, signs and symptoms, mode of transmission, treatment and vaccine, $3^{\text {rd }}$ part (23-33 questions) to assess student's knowledge regarding prevention and precautions measures regarding COVID19 and $\underline{4^{\text {th }} \text { part }}$ (34-44 questions) to assess student's knowledge regarding protocol of treatment and procedure in case of +ve COVID19.

Scoring system for theoretical part, according to references\& articles were predetermined the correct answers. Each theoretical question was given a mark and the total score of information was obtained for each study subject as follows; for the theoretical items, a correct answers was scored (1) mark and the incorrect answer was scored (zero) mark. For each question, all marks of the answers were summed-up and the total score divided by the number for the questions, giving a mean score for the theoretical part. All scores were analyzed into percentages, and means were computed. Answer was considered correct if the percent score was $60 \%$ or more and incorrect if less than $60 \%$.

\section{Observational checklists for student performance contained the following:}

\section{A. A standard practice list for hand rub procedure:}

It was constructed according to Ministry of Health guidelines 2020, to assess practices of hand rub after instruction by 1 and 2 month of study. It was included (7) step for hand rub each step has score (2).

\section{B. A standard practice list for removing sterile gloves procedures:}

It was constructed according to Ministry of Health guidelines 2020, to assess practices of removing gloves after instruction by 2 month of study. It was included (8) step for removing sterile gloves each step has score (2). 


\section{A standard practice list for wearing mask procedure:}

It was constructed according to Ministry of Health guidelines 2020, to assess practices of wearing mask after instruction by 1 and 2 month of study. It was included (6) step for wearing mask each step has score (2).

\section{A standard practice list for removing mask procedure:}

It was constructed according to Ministry of Health guidelines 2020, to assess practices of removing mask after instruction by 1 and 2 month of study. It was included (3) step for removing mask each step has score (2).

Scoring system: for practical evaluation for all procedures by the following;

The satisfactory steps done were scored " 2 " and the unsatisfactory steps done were scored " 1 " and step not done were scored " 0 ". For each performance, the practical performance were summed-up and the total evaluation divided by the number for the steps, giving a mean score for the practice. These scores were changed into a percentage, and means were computed. The satisfactory practice was considered $60 \%$ or more and unsatisfactory practice if less than $60 \%$.

\section{Operational Design}

\section{Preparatory Phase (Phase 1):}

It was included conducting brain storming as a quality tools for all research team to collect ideas about the subject and distribute tasks and responsibilities to all team members before starting study. Then we began searched current and past, local, national and international related research title and theoretical information of different respects of the study using periodicals, magazines, text books, articles and internet to develop appropriate quality tools for data collection and results. This review helped the researchers to be acquainted with magnitude of the study and guided the researchers to prepare data collection quality tools. In this stage the researchers was developed the questionnaire sheet and observation checklists on bases of literature review.

Content validity: There were quality tools of data collection which adopted from previous studies and Ministry of Health guidelines and modification was considered. It was revised by jury of expertise and supervisor in specialty of quality diploma of Health care Services and their comments were considered.

\section{Field Work (Phase I1):}

The process of data collection carried out in the period from the first day of December 2020 until the end of January 2021, so the study was stayed two months. The sample size was included in the study; all eligible students were 120 female students' nurses. Included the researchers were met the previously mentioned study sitting 4 days every week. This phase was concluded three stages: 


\section{Stage I:}

- Firstly, the objective of the study was clarified to all first and second year academic female students to gain their trust and confidence to participate in the study. Consent of each female adolescent was obtained orally to participate in the study.

- After that, the researchers divided the student in two groups: $\left(1^{\text {st }}\right.$ year students and $2^{\text {nd }}$ year students) to clarify and discuss the methods of answering questionnaire sheet by using internet system online for data entry with each group separated from others.

- Next, each researcher interviewed each group separately; the duration of each interview was spending 1 hour to answer the questionnaire form through online. And divided each group into six groups for collecting observational performance checklist in the skills lab.

- Then, data was collected within the study day, it was been in between sessions, or at the end of the day after finishing sessions, It was spend 2 hrs., start from 1 pm until 3 pm afternoon within four days each week.

- Each researcher was interviewed $1^{\text {st }}$ and $2^{\text {nd }}$ group student nurse separated in the lecture halls using internet system through Google form sheet to assess students' general characteristics and their Knowledge regarding COVID19.

- After that, each researcher assessed each student (in groups) by the quality tools of; hand rub examination, removing sterile gloves examination, wearing and removing mask examination regarding preventive measures of COVID19 using designed different quality tools pre intervention in the same setting.

- Next, an observational checklist was utilized to evaluate each student nurses skills regarding preventive measures of COVID19.

\section{Stage II (implementation phase):}

- Firstly, the researchers were classified the student into 12 groups, each group include 10 students. 7 groups in the $1^{\text {st }}$ academic year in Health Technical Institute (74 students). 5 groups in the Health Technical Institute (46 students). The last group consists of four students from $1^{\text {st }}$ year academic student and six students from $2^{\text {nd }}$ year academic student.

- The practical examination was included hand rub examination, removing sterile gloves examination, wearing and removing mask examination about preventive measures related COVID19 procedures.

- Then, each researcher was clarified and explained the practical examination which required in the study for each group.

- Next, the researchers were planned the four evaluation sessions in theoretical parts and six sessions in practical parts in the form of one session every day (four day every week).

- Theoretical session evaluation divided into two sessions, every session 
was taking one hour for each group, every day one group, Schedule session was four days / week.

- Practical session divided into 12 sessions, for student's examination without re-demonstration because these practical skills included in their educational course specs and educational content while studying at institute. And all students already hold a nursing diploma before joining the institute.

\section{Stage III (Evaluation phase):}

- At the end of distribution and planning of theoretical and practical schedule sessions the researchers started to assess the knowledge and practice for students using predetermined quality tools format for student nurse by interview using the same quality tools according to plan.

- The researchers done the evaluation of student's knowledge regarding COVID19 using online questionnaire sheet form during interviewed each group separately to collect student's answers and to guide the students while performing the evaluation.

- Within one month post interview the researchers evaluate the performance nurse utilization of preventive measures regarding COVID19 using the previous same intervention format using the predetermined quality tools to evaluate COVID19 practices.

- Reinstruction was done as needed in the period of one month to assure their understanding for their practices of all procedures accurately. An observational check list was used to evaluate their practices.

- The researchers done examination in the skill lab after theoretical session evaluation in the same day to guide the female while performing the procedures according predetermined plan with the groups.

- The last group was examined their practical performance through recording videos through internet for each student in this group separately.

- Then, each student sent her recorder videos for each four procedures then the researchers were evaluated students' performance online, because of the issuance of a decision by the presidency of the republic to complete the study remotely and to prevent students from gathering in educational institutes.

- After that, the researchers were done collecting the answers of all students about questionnaire sheet and represented the evaluation by using Google system in the form of pie chart with percentage for each answer.

- At the end, the researchers were done code numbers for each observational check list and by using SPSS program on excel program in computer the performance evaluation form were arranged and represented graphically in the form of histogram, and expressed in percentage terms. 


\section{$\underline{\text { Ethical consideration }}$}

Scientific Research Ethical Committee in Sadat Academy for Administrative Sciences and Technical Health Institution general manger was gave researchers the research approval before starting study. The researcher was explained the purpose and objective of the study to nursing students who participated in the study. The researchers were assured maintaining secrecy and identity of subject data. The participants were informed that they are free to decide to accept or refuse in the study and they have the right to incomplete the study at any time. The researchers were obtained Students' consent for their participation. The nature of the study was harmless.

\section{Limitations of the study}

There were dropped out 4 cases in the attendance in skills lab of the female student during the implementation of practical evaluation. So the researchers were obtained the results of performance evaluation through videos recording by using internet. There were two student had +ve COVID19 during the implantation period of the study, and evaluation was obtained from those students also, through videos recording using internet.

\section{$\underline{\text { Results }}$}

Figure (1): frequency distribution according to self-reported students' sources of information about COVID19 $(\mathrm{N}=120)$

Figure (1) showed that, $(53.3 \%)$ of students had their information from social media, while students had their information from health team, T.V, friends and relatives and training \& lecture represents $(21.7 \%, 19.2 \%, 3.3 \%$ and $2.5 \%)$ respectively.

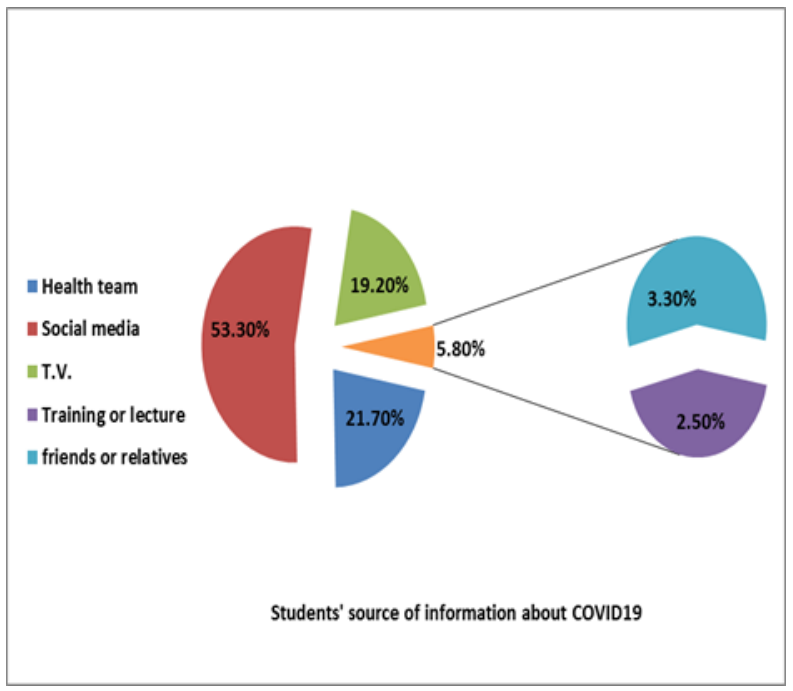


Table (1): Frequency distribution of students' sample related to concepts, causes, signs and symptoms and mode of transmission regarding COVID19. $(\mathrm{N}=120)$

\begin{tabular}{|l|c|c|c|}
\hline \multicolumn{1}{|c}{ knowledge regarding COVID19 as a disease } & YES & No & $\begin{array}{c}\text { I don't } \\
\text { know }\end{array}$ \\
\hline Is COVID19 among the respiratory syndrome? & $91.7 \%$ & $3.3 \%$ & $\mathbf{5 \%}$ \\
\hline Do you know the meaning of a pandemic? & $75.8 \%$ & $10.8 \%$ & $\mathbf{1 3 . 3 \%}$ \\
\hline Do you know what COVID19 stand for is? & $68.3 \%$ & $14.2 \%$ & $\mathbf{1 7 . 5 \%}$ \\
\hline Does a person get infected through: & \multicolumn{3}{|c|}{} \\
The droplets from the patient during coughing or sneezing & $100 \%$ & 0 & $\mathbf{0}$ \\
Direct contact with the infected person & $93.3 \%$ & $0.8 \%$ & $\mathbf{5 . 9 \%}$ \\
Touching contaminated surfaces and tools & $92.5 \%$ & $7.5 \%$ & $\mathbf{0}$ \\
\hline Are the following symptoms is a symptom of COVID19? & \multicolumn{3}{|c|}{} \\
Hyperthermia & $\mathbf{9 9 . 2 \%}$ & $\mathbf{0}$ & $\mathbf{0 . 8 \%}$ \\
Diarrhea & $\mathbf{8 7 . 5 \%}$ & $\mathbf{4 . 2 \%}$ & $\mathbf{8 . 3 \%}$ \\
Dyspnea & $\mathbf{9 7 . 5 \%}$ & $\mathbf{1 . 6 \%}$ & $\mathbf{0 . 9 \%}$ \\
Runny nose & $\mathbf{6 1 . 7 \%}$ & $\mathbf{3 1 . 7 \%}$ & $\mathbf{6 . 6 \%}$ \\
Sore throat & $\mathbf{9 2 . 5 \%}$ & $\mathbf{2 . 5 \%}$ & $\mathbf{5 \%}$ \\
Headache & $\mathbf{7 9 . 2 \%}$ & $\mathbf{1 1 . 7 \%}$ & $\mathbf{9 . 2 \%}$ \\
Vomiting & $\mathbf{5 5 \%}$ & $\mathbf{2 5 . 8 \%}$ & $\mathbf{1 9 . 2 \%}$ \\
\hline
\end{tabular}

Table (1) showed that, the results of students' knowledge about COVID19 is among the respiratory syndrome were $(91.7 \%)$, and there were $(75.8 \%)$ of students knowing the meaning of a pandemic. All of students were knowing that person get infection through droplets from the patient during coughing or sneezing, on the other hand the majority of students represented(99.2\%) were knowing the hyperthermia is a symptom of COVID19.

\section{Table (2): Distribution of students' knowledge in the study sample according to Prevention and precautions measures $(\mathrm{N}=120)$}

\begin{tabular}{|l|c|c|c|}
\hline \multicolumn{1}{|c}{ How can you prevent disease (How do I protect myself): } & YES & No & $\begin{array}{c}\text { I don't } \\
\text { know }\end{array}$ \\
\hline Maintaining the safe distance about one meter & $92.5 \%$ & $5.8 \%$ & $\mathbf{1 . 7 \%}$ \\
\hline Use of hand sanitizers & $99.2 \%$ & $0.8 \%$ & $\mathbf{0}$ \\
\hline $\begin{array}{l}\text { Make sure to cover your nose and mouth while coughing or sneezing } \\
\text { with tissues }\end{array}$ & $99.2 \%$ & $0.8 \%$ & $\mathbf{0}$ \\
\hline Avoid direct contact with possible or +ve COVID19 patients & $96.7 \%$ & $3.3 \%$ & $\mathbf{0}$ \\
\hline Avoid direct contact with health workers & $95 \%$ & $3.3 \%$ & $\mathbf{1 . 7 \%}$ \\
\hline Avoid touching the nose, mouth and eyes with contaminated hands & $\mathbf{9 9 . 2 \%}$ & $\mathbf{0 . 8 \%}$ & $\mathbf{0}$ \\
\hline
\end{tabular}

Table (2) showed that, the results of students' knowledge about (use of hand sanitizers, cover nose and mouth while coughing or sneezing with tissues and avoid touching the nose, mouth and eyes with contaminated hands) represented (99.2\%). And their knowledge about the safe distance is one meter represented 
(92.5\%), on the other hand their knowledge about avoid direct contact with possible or +ve COVID19 patients represented (96.7\%).

Figure (2): frequency distribution according to self-reported students' knowledge that there is a vaccine against $\operatorname{COVID19}(\mathrm{N}=120)$

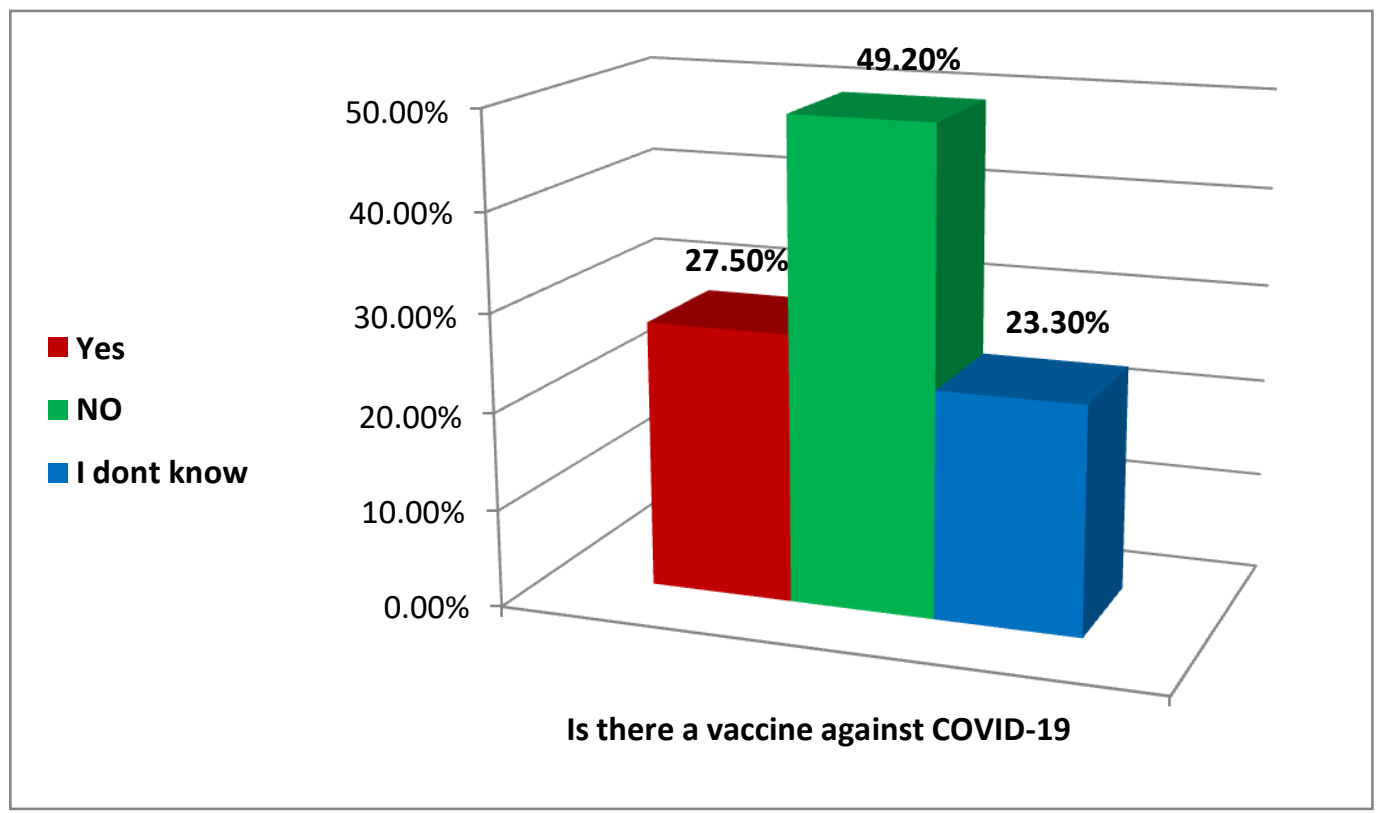

Figure (2) showed that, the percentage of students' knowledge were known that there isn't a vaccine against COVID19 represented (49.20\%).

Figure (3): frequency distribution according to self-reported students' knowledge that there is a treatment for COVID19 $(\mathrm{N}=120)$

Figure (3) showed that, the percentage of students' knowledge were known that there is a treatment for COVID19 represented $(42.50 \%)$

Figure (4): frequency distribution of

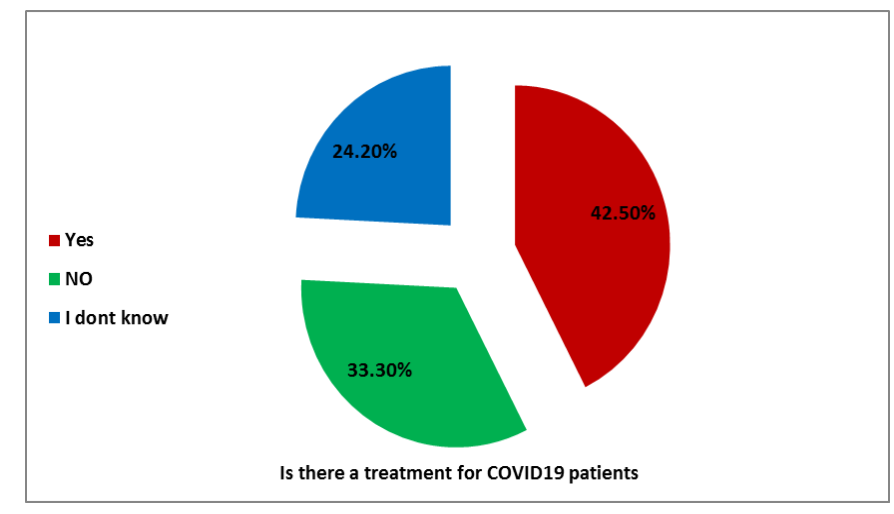
students' knowledge for preemptive actions related to COVID19

Figure (4) showed that, all of sample size have a positive knowledge about preemptive actions (washing hands, wearing mask, surfaces disinfection, avoid crowded places and safe disposal of contaminated tissue) related to COVID19 represented (100\%).

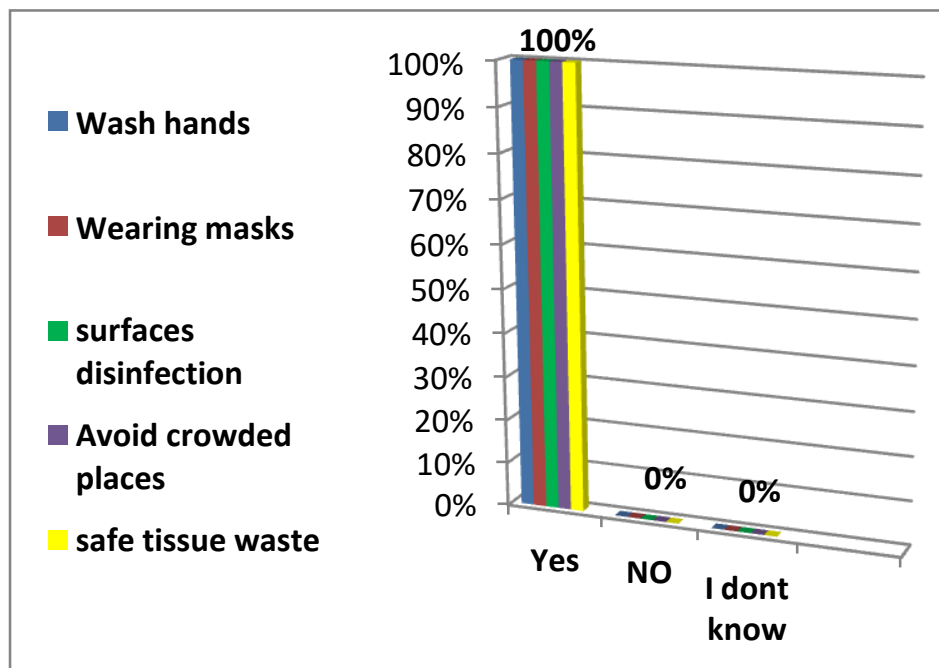


Figure (5): Total students' preventive practices regarding COVID19

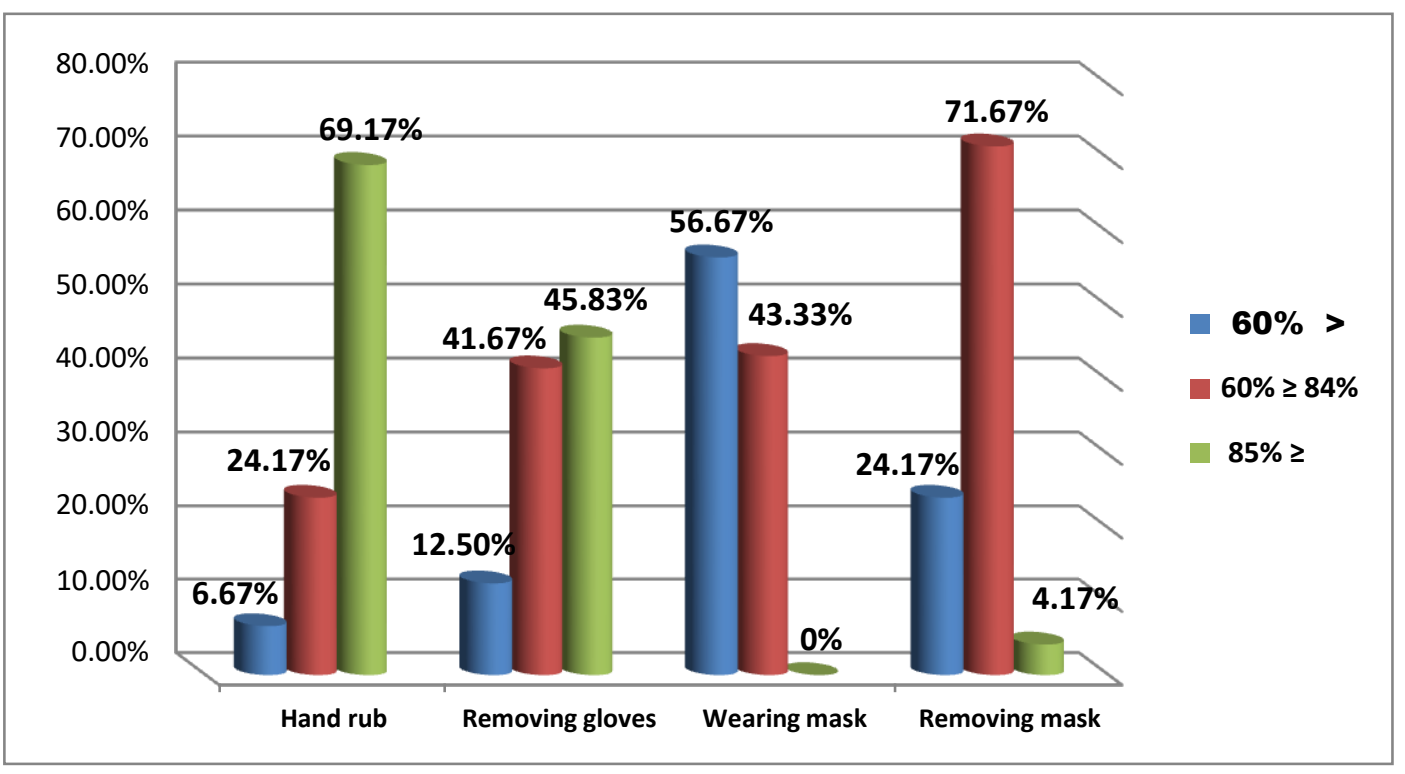

$\mathrm{Fi}$ gure reveal ed that, more than half $(69.17$ $\%$ of studen ts'

practice in hand rub demonstrated highly prevalence ( $85 \%$ and more), also nearly half $(45.83 \%)$ of students' practice in removing gloves demonstrated highly prevalence (85\% and more).However, about half $(56.76 \%)$ of students' practice in wearing mask demonstrated low prevalence less than $60 \%$.

\section{$\underline{\text { Statistical Design }}$}

Statistical description of collected data were presented in the form of frequencies and percentage for qualitative variables. These variables were compared between the total sample size and after evaluation. Statistical significance was considered. These data were organized and analyzed using appropriate statistical significant tests.

\section{Discussion}

The descriptive study was conducted to test a research question of using quality tools have positively effect on assessment of student's knowledge and practice regarding COVID 19. Various quality tools used during implementation of study including brain-storming sessions, questionnaire sheets, observational checklists, bar chart, pie chart and histogram.

From results, it is clear that the authors were developed questionnaire sheet and four observational checklists as a quality tools for data collection by brain storming tool and also, they used bar chart, pie chart and histogram diagram for clarifying the results.

The bar chart as a quality tool helped authors to revealed that our findings were agreement with China study results of COVID-19 which showed that the 
study sample was university students and majority of them had good knowledge about the main clinical symptoms, methods of prevention, treatment, vaccine unavailability and control of COVID-19 (Zhong B-L. et al., 2020, Huang C. et al., 2020, Dhama K. et al., 2020).

The previous finding also similar to study done by (Ahmed S., A., et al, 2020) in Egypt their study sample was Egyptian public who evaluate the their knowledge, perceptions and attitude related to COVID-19 disease, which revealed that their study sample had good general knowledge about the methods of spread, and prevention related to COVID19 which provided by the WHO and the Egyptian Ministry of Health to the public.

Also, it was conclude from our finding that, all sample size have a positive knowledge related to preemptive actions of COVID19 and were extremely cautious represented (100\%) which include; avoided crowded places and wearing masks when going out the home during the period of the outbreak. This results could be due to the study sample obtained their knowledge from an accurate and reliable source of information in addition to having a nursing diploma. A similar study carried out in China on university students and showed that their university students avoided crowded places represented (96.4\%) and wore masks upon departing their homes during the outbreak of COVID-19 represented (98.0\%) (Zhong B-L. et al., 2020).

Moreover, our finding receiving nearly all study sample showed their commitment about primitive actions regarding COVID19. So, a very high percentage of positive responses in current study is very encouraging because of information about preemptive action as washing hands, surfaces disinfection, and safe disposal of contaminated tissues are represented (100\%) while, knowledge about the methods of transmission represents (93\%). This result was incongruent with Indian study that it was relatively low percentage $(68 \%)$ of information on the modes of transmission and almost half of their sample size represented (59\%) about the knowledge of the staying alive of SARS-CoV-2 on any surfaces. (Jagajeet P.,et al., 2020).

Also, our finding was similar to (Reuben et al., 2020), who showed that Most of the study sample had responses towards the preventive measures including wearing face mask in crowded areas, social distancing, and personal hygiene.

Moreover, the current study was similar to the study done by (Honarvar et al., 2020) who showed that more than $80 \%$ of the sample size applying hand washing technique, more than half $(70 \%)$ of their public survey did the preemptive actions to prevent COVID-19 infection, and more than $60 \%$ of them weared a face mask and removed it correctly. However, more than half of them 
did not maintain a safe social distance and almost $75 \%$ of them had travel out of the city during two weeks before this study.

In addition to, our finding showed that a social media play an important role in spreading and providing information. So now days is a vital source of student knowledge which represented $(53.30 \%)$ of technical students and followed by TV represented $(19.20 \%)$ of them were their primary sources of information related to COVID19. while students had their information from health team, (friends \& relatives) and (training or lecture) represents $(21.70 \%, 3.30 \%$ and $2.50 \%)$ respectively. This results similar to India study which revealed that the majority of their students obtained from the knowledge about COVID-19 from social media as a primary source of disseminating information (Jagajeet P.,et al., 2020).

Also, our finding was agreed with a study done by (Ahmed S., A., et al, 2020) who indicated that, The most common sources among adult Egyptians of information were social media represented $(66.9 \%)$, the internet represented $(58.3 \%)$ then TV/satellite channels represented (52.6\%). Other sources among adult Egyptians were (friends or family members), medical personnel and newspapers represented $(38.1 \%, 35.4 \%, 6.3 \%)$ respectively.

This study finding illustrated that students respondent, answered that the common symptoms of coronavirus are hyperthermia, dyspnea, and sore throat $(99.2 \%, 97.5 \%, 92.5 \%)$ respectively. but $(42.5 \%)$ believed that right now there is no effective cure for Covid-19, (99.2\%) believed that isolation and quarantine are effective ways to prevent the spreading of COVID19 this finding was agreement with India study their results illustrated that, students knew that breathing difficulties, shortness of breath, fever and cough, are the main symptoms for COVID-19 represented (91\%). On the other hand, the students knew that direct contact with infected people, droplets from infected people and touching contaminated objects or surfaces are methods from personto-person transmission represented (68\%) (Jagajeet P.,et al., 2020).

Our flinging was disagreed with the finding of a study done by (Samira $\boldsymbol{E}$. E. and, Entisar A. E., 2020) assessed public knowledge, practice and attitude regarding COVID-19 pandemic in Al Gharbia Governorate, Egypt who stated that, the most of $(89.1 \%)$ their sample size had good information related to COVID19. Also, TV was the commonest source (77\%) followed by social media (67.10\%) for this knowledge. Also, half $(50 \%)$ of them had reported poor practices regarding COVID-19.

\section{Conclusions}

Quality tools (Brain Storming, Observational Checklist, Questionnaire Sheet, Bar Chart, Pie Chart and Histogram) was used in the study have positive effect on assessment of student's knowledge and practice regarding COVID 19 
among Health Technical Institute students.

\section{Recommendations}

In the light of our study findings, the following recommendations were suggested:

- Design primitive actions guideline for Technical Health Institute students to update their knowledge and practice regarding COVID19.

- Implement program training for all departments of Technical Health Institute students to improve their knowledge and practice regarding COVID19.

- Ministry of education in cooperation of Ministry of health must be integrated guideline in the educational strategies for all educational stages to improve their awareness about the importance of primitive actions regarding COVID19.

List of abbreviation: COVID19: Corona Virus Disease of 2019

\section{References:}

Ahmed S. A., Zeinab M., Maha E. I., Hany H. Z., Mohamed A., Mohamed A., \& Eman A. S., (2020): Knowledge, Perceptions, and Attitude of Egyptians Towards the Novel Coronavirus Disease (COVID-19) Journal of Community Health, 31 August. The online version of this article (https ://doi.org/10.1007/s1090 0-020-00827 -7)

> Chen N., Zhou M., Dong X., Qu J., Gong F., Han Y., \& Zhang L. (2020): Epidemiological and clinical characteristics of 99 cases of 2019 novel coronavirus pneumonia in Wuhan, China: A descriptive study. The Lancet, 395(10223), 507-513. https://doi.org/10.1016/S0140-6736(20)30211-7

> Dhama K., Sharun K., Tiwari R., Dadar M., Malik YS., \&Singh KP, (2020): COVID-19, an emerging coronavirus infection: Advances and prospects in designing and developing vaccines, immunotherapeutics, and therapeutics. Hum Vaccin Immunother. Mar 18:1-7. Published online.

> Honarvar B., Lankarani K B., Kharmandar A., Shaygani F., Zahedroozgar M., Haghighi, MR.,Ghahramani S., Honarvar H., Daryabadi MM., Salavati Z., Hashemi SM., Joulaei H., \& Zare M. (2020): Knowledge, attitudes, risk perceptions, and practices of adults toward COVID-19: a population and field-based study from Iran. International Journal of Public Health. (https://doi.org/10. 1007/s00038-020-01406-2).

$>$ Huang C, Wang Y., Li X., Ren L., Zhao J., \& Hu Y., (2020): Clinical features of patients infected with 2019 novel coronavirus in Wuhan, China. Lancet.; 395:497-506. [PMC free article] [PubMed] [Google Scholar]

$>$ https://www.goodrx.com/blog/what-does-covid-19-mean-who-named-it/. 
> Jagajeet P., S., Anshuman S.,and Shiv D., G.,(2020): Assessing the Knowledge, Attitude and Practices of Students Regarding the COVID-19 Pandemic Institute of Health Management Research, Journal of Health Management 22(2) 281-290, $3^{\text {rd }}$ ed., Indian.

> Kerzner, H. (2009): Project Management: A Systems Approach to Planning, Scheduling, and Controlling $10^{\text {th }}$ ed., Hoboken, New Jersey: John Wiley \& Sons, Inc.

> Neyestani B. (2017): "Seven Basic Tools of Quality Control: The Appropriate Quality Techniques for Solving Quality Problems in the Organizations, March- 175,247.” https://doi.org/10.5281/zenodo.400832.

$>$ Peng Y., Pei C., Zheng Y., Wang J., \& Zhang K. (2020): Knowledge, attitude and practice associated with COVID-19 among university students: A crosssectional survey in China. BMC Public Health, 127, 1-24. (https://www.researchsquare.com/article/rs-21185/v)

$>$ Reuben RC., Danladi MM., Saleh DA., \& Ejembi PE., (2020): Knowledge, Attitudes and Practices Towards COVID-19: An Epidemiological Survey in North-Central Nigeria. Journal of Community Health.

(https://doi.org/10.1007/s10900-020-00881-1)

$>$ Samira E. E. and Entisar A. E., (2020): Public's Knowledge, Attitude and Practices regarding COVID-19 Pandemic in Al Gharbia Governorate, Egypt. Tanta Scientific Nursing Journal, Vol. 19 No. 2 November.

$>$ WHO (2020a): Rolling updates on Coronavirus disease (COVID-19). https://www.who.int/emergencies/diseases/novel-coronavirus-2019/eventsas-they-happen Google Scholar

$>$ www.preprints.org, 2020.

$>$ Zhong B-L, Luo W, Li H-M, Zhang Q-Q., Liu X-G., \& Li W-T., (2020). Knowledge, attitudes, and practices towards COVID-19 among Chinese residents during the rapid rise period of the COVID-19 outbreak: A quick online cross-sectional survey; 6:1745-52. 